Ensayo Original / Original Essay

\title{
Docencia y Dignidad del Alumno
}

\author{
Autor: Ciro Hernández Valderrama \\ Instituto Universitario de Tecnología Puerto Cabello, IUTPC \\ cirohv@hotmail.com \\ Puerto Cabello, Venezuela \\ https://orcid.org/0000-0003-3933-262X
}

\section{Resumen}

A comienzos de un nuevo milenio, la civilización mundial inmersos en un conglomerado de fenómenos científico-tecnológicos y socio-culturales que los envuelve en ambiente de dudas e insatisfacciones, afronta novísimas formas de pensar, apropiación de experiencias, nuevos esquemas de vida y conocimiento; la formación del individuo dentro del sistema educativo de cualquier país no escapa de ello, sus actores fundamentales profesores y alumnos se encuentran envueltos en profundas dicotomías entre lo convencional y un entramado mundo de nuevos valores personales y colectivos. Este ensayo resultado reflexivo de una investigación educativa con enfoque cualitativo, expone el tema de la acción docente dentro del contexto educativo formal, con pretendido de tejer el referente de valoraciones que construye el docente en su desempeño, acerca de la semántica implícita en la noción de dignidad del alumno, en el contexto de la Educación Venezolana. Subyace la idea orientadora de fomentar la reflexión, atinente al respeto y convivencia humana entre los actores. Permite clarificar el camino que seguirá la visión de dignidad de los estudiantes en el seno de la enseñanza formal en los predios académicos y el debate del campo axiológico centrado en la unión y la convivencia planetaria. Asimismo, la necesidad de reflexionar, acerca de actitudes y posturas de valor que en el campo personal, social y educativo tienen profesores y alumnos.

Palabras clave: formación; estudiante; docencia; educación formal. 


\title{
Teaching and Dignity of the Student
}

\begin{abstract}
At the beginning of a new millennium, the world civilization immersed in a conglomerate of scientific-technological and socio-cultural phenomena that surrounds them in an environment of doubts and dissatisfactions, faces new ways of thinking, appropriation of experiences and new schemes of life and knowledge; the formation of the individual within the educational system of any country does not escape from it, its fundamental actors teachers and students are involved in deep dichotomies between the conventional and a network of new personal and collective values. This essay is a reflexive result of an educational research with a qualitative approach, expose the topic of the teaching action within the formal educational context, with the intention of weaving the reference of evaluations that the teacher constructs in his performance, about the semantics implicit in the notion of the student's dignity, in the context of the Venezuelan Education Underlies the guiding idea of promoting reflection regarding respect and human coexistence among the actors. It allows to clarify the path that will follow the vision of dignity of the students in the heart of the formal education in the academic premises, and the debate of the axiological field centered in the union and the planetary coexistence. Also, the need to reflect on attitudes and positions of value, that in the personal, social and educational field have teachers and students.
\end{abstract}

Keywords: training; student; teaching; formal education. 


\section{Introducción}

En la actualidad el profesorado, alumnado y la sociedad toda se encuentran inmersos en un conglomerado de fenómenos científicotecnológicos y socioculturales que los envuelve en un ambiente de dudas e insatisfacciones. El individuo pareciera haber perdido la brújula que lo guíe hacia el encuentro con la formación escolar y plenitud personal. En este verdadero desconcierto, se intuye el olvido sociocultural dentro del discurso académico científico de que el ser humano, no sólo posee una facultad cognoscitiva, con la que emite juicios, sino que también es capaz de estudiar, valorar las cosas, los hechos, las personas y juzgar sobre ellos.

En este contexto, la gran preocupación del hombre frente a la complejidad de los fenómenos naturales y por el hecho de convivir en grupo formando sociedades, encierra toda una ontología expectante, dentro de la cual ha estado implícito el organismo vivo como activador de sus propios espacios educativos, emocionales, de lenguaje y convivencia que le ha correspondido construir. Por ello, la inquietud humana por estudiar estas situaciones problemáticas, parece estar relacionada con dimensiones de experiencias surgidas del propio medio laboral, del aula. El autor, activo desde hace 30 años, plantea la necesidad de dilucidar inquietudes e impresiones, que en resumen han brindado vivencias con demás colegas y alumnos de varios niveles de formación.

Cuando se trata de enseñar conocimientos e instruir en procedimientos y técnicas desde cualquier disciplina científica, hoy no parece ser comprometido, porque cualquier profesional universitario puede hacerlo. Sin embargo, cuando el objetivo verdadero es formar ciudadanos cultos y críticos, e ir más allá del simple aprendizaje de proveer contenidos, información y comunicación, el asunto no parece fácil, ya que se pretende educar para la vida.

En tal sentido, la tarea consiste en tomar decisiones en procura del 
bienestar estudiantil, y hacer honor a la etimología del término "docencia" traducido como acción escolar, en el que los actores principales docentealumnos generan clima de intercambio de valores, dentro del cual lo humano como condición inherente a la naturaleza de la persona, ocupa en el espacio educativo un lugar preponderante, definiendo derechos deberes y libertades de cada uno de los estudiantes y profesores. Es dentro de este horizonte axiológico presente en el escenario educativo venezolano, que el tratamiento de la dignidad adquiere importancia para la persona como ser sociocultural humano.

\section{Dignidad, naturaleza del ser humano}

La definición básica que tiene del término dignidad, en su acepción etimológica, aplica varias terminaciones verbales y adjetivas que hablan del significado asignado, es así como el Diccionario de la Real Academia Española (2001a), refiere: "Dignidad: (Del lat. Dignitas, cualidad de digno. Excelencia, realce. Digno (na): correspondiente, proporcionado al mérito y condición de alguien que tiene dignidad o se comporta con ella" (pág. 1).

Según lo descrito, la definición de dignidad siempre abre un abanico de significados y ponderaciones. En concordancia con esto, la educación formal privilegia la dignidad como el derecho universal que adquiere todo individuo a ser tratado con justicia, por el hecho de ser humano y ocupar un espacio sociocultural. Es digno de merecer los beneficios socioculturales y económicos de una sociedad, toda persona que conviva y comparta dentro de ella.

Visto de este modo, todo estudiante que participe en el proceso educativo es merecedor de estima a su dignidad, es decir, durante el acto de aprendizaje escolar, merece ser tratado en atención a las normas de convivencia de la institución escolar, del Estado Nación y organismos internacionales. Es en el proceso humano de interrelación compartir-convivir educativo, que los actores muestran la verdadera naturaleza del ser docente 
y ser digno en presencia, participación y protagonismo.

Se trata del vivir en el convivir (VICONVI), es decir, el acto sublime, espontaneo y natural de la especie humana, (un tanto olvidado) en el cual transcurrió su modo de vida y su mundo desde que vivió como primate bípedo, en una especie de relación multidireccional entre todos los miembros del grupo, creando lazos afectivos inseparables. En el actual mundo "civilizado" este modo de vida, parece estar desapareciendo.

Conviene destacar, que asociado al concepto de dignidad, está el término respeto, cuyo significado según el Diccionario de la Real Academia Española (2001b): es el de "Veneración, acatamiento que se hace a uno. Miramiento. Consideración. Atención. Manifestaciones de acatamiento que se hacen por cortesía" (pág. 1). De modo que en la acción docente, respetar la dignidad, es un acto de rigor natural humano entre protagonistas de un proceso de formación.

La dignidad de la persona aparece definida por la Santa Biblia (1985):

En las epístolas de los apóstoles, San Pedro (Cap. II, V-21), invita a ser más sincero y sin malicia, como los niños y a que se porten según la dignidad que les confiere ser hijos de Dios; porque...fuisteis llamados a la dignidad de hijos de Dios. Por su parte San Judas, en la epístola católica (V-8) exhorta a la constancia en la fe, y a resistir en los esfuerzos y ardides de los impíos por cambiar la gracia de Dios sin respetar ni dignidad ni jerarquía. Advierte que se irrespeta la dignidad cuando se mancilla la carne y blasfema contra la majestad de Dios (pág. 1227).

Se aprecia entonces, en este precepto bíblico el respeto sublime a Dios y la indiferencia implícita cuando se agrede moral o físicamente a otra persona. Asimismo, para comprender el sentido de dignidad, Villegas (s.f.), afirma que: "El rasgo más original de la visión bíblica de la dignidad del hombre, es que ella es vulnerable. Por eso debe ser afirmada, aun en medio del dolor y la injusticia" (pág. 5). Oportuno es preguntarse si esta caracterización de 
dignidad del hombre, significada en los planes de Dios, al adjudicarle el máximo protagonismo en su obra de creación, es asumida en la actualidad como orientación moral y patrón de consideración hacia las personas en los procesos educativos.

Es posible que estos argumentos atribuidos al hombre, no sean visualizados en la vida social y educativa de la actualidad; dado el origen de dignidad que lo emparenta con Dios y que está por encima de todas las cosas, disponer de ellas para su servicio, y constituir él mismo una ventana abierta a los designios del Supremo Dios y estar vinculado por la fe con su Creador.

Se evidencia, que las representaciones atribuidas a la expresión dignidad son, algo más que un valor personal o colectivo, encierra toda una compleja ontología teológica por comprender el significado existencial del hombre en el planeta. Al respecto, la definición de condición según el Diccionario de la Real Academia Española (2001c), refiere: "estado, situación especial en que se halla alguien. Calidad del nacimiento o estado de los hombres" (pág. 1). De esto se desprende que los individuos desde antes de nacer, adquieren el estado de ser dignos de todos los derechos humanos otorgados por la sociedad.

Por su parte, Penalva (2006), explicita la noción de dignidad: "El mayor ideal que puede alcanzar el hombre es conquistar la propia dignidad. La mayor felicidad reside en que el hombre consiga ser dueño de sí mismo" (pág. 163).

Si lo afirmado se lleva al espacio educativo, los educadores deben ser los primeros en tener conciencia por conquistar su propia dignidad, toda vez que la enseñanza verdadera debería comenzar por la propia formación e intencionalidad de los profesores, pues sus palabras, imágenes y actitudes personales constituyen ejemplo a seguir por estudiantes. Se comprende pues, que la capacidad de conciencia de un docente en ejercicio, se adquiere en la confluencia relacional con el entorno socio-educativo. Es obvio entonces, que la disposición o intencionalidad en su desempeño, constituye un refuerzo 
subjetivo que emerge per se, de la conciencia adquirida en los predios educativos.

A la luz de esta racionalidad, es oportuno destacar el imperativo de la naturaleza humana, (constituido por la trascendencia existencial) sobre los demás seres del planeta; per se, el humano está dotado de dignidad, capacidad intelectual y virtudes propias, que le permiten con pensamiento y obra transponerse más allá de la naturaleza física y material, en la búsqueda infinita por la cosmovisión de vida.

Estas ideas, pueden tener alguna explicación en el proceso educativo, en el sentido que los sujetos, llegan a comprender por intuición lo que representan como alumnos, docentes, compañeros de clase o amigos, y tienden a ser más felices y dueños de sí mismo. Sin duda, estas condiciones son indicadores de la propia dignidad y por ende, de la naturaleza del individuo y la parte humana. Aquí se infiere, que en el espacio educativo debe prevalecer la benevolencia del profesor sobre las expresiones soeces que suelen presentarse con los alumnos.

En el marco de los planteamientos precedentes, cabe destacar la correspondencia conceptual de éstos, con lo planteado por el Ministerio del Poder Popular para la Educación en el Currículo Básico Nacional Bolivariano (2007a), el diseño de este nuevo sistema de educación, designa el desarrollo de la persona y el respeto a su dignidad a través del "aprendizaje experiencial, transformacional, por descubrimiento y por proyectos" (pág. 43). Un fin por demás, perseguido por el Estado, en la Constitución de la República Bolivariana de Venezuela (1999a): a manera de ilustrar se establecen en el mismo, cuatro pilares fundamentales para el desarrollo integral del nuevo ser social humanista: "Aprender a Crear, Aprender a Convivir y Participar, Aprender a Valorar y Aprender a Reflexionar" (pág. 16). El significado de estos cuatro pilares aborda un extenso horizonte axiológico del proceso educativo: supone para los estudiantes y docentes el respeto mutuo a la necesidad de 
merecer como humanos, el desarrollo de cualidades creativas, valores, actitudes y las virtudes inherentes a la democracia plena.

Ante la percepción de dignidad descrita, la educación formal podría consolidar el carácter humanizador, sustentando el quehacer en lo humano, que valora y dignifica la personalidad. Esta perspectiva escolar concuerda con la del Ministerio del Poder Popular para la Educación en el Currículo Básico Nacional Bolivariano (2007b), el cual establece: "La escuela se erige, en un centro del quehacer teórico-práctico, integrado a las características sociales, culturales, reales del entorno; en el cual los actores sociales inherentes al hecho educativo dialogan, reflexionan y discuten sobre el sentir" (pág. 48). Dentro de esta concepción humanista, la realidad ontológica del proceso educativo promueve la identidad personal, social y cultural.

El concepto dignidad, parece abarcar diversas significaciones según, se lo utilice en los complejos contextos de la vida diaria, sin embargo, para el ámbito del proceso de enseñanza y aprendizaje del sistema educativo venezolano está relacionado con el desempeño del docente, y en conjunción con el término respeto, articula el sintagma respeto a la dignidad del alumno.

La voz latina dignitas en el contexto histórico romano, constituye una definición signada a la vida política, e impregnado de moralidad. Es obvio que la semántica del término dignidad ha evolucionado, en la era medieval también fue utilizado para enaltecer personajes.

En el caso del hombre dignidad reside en el hecho de que es objetividad social, del hombre ser único ontológico, insustituible como persona, dotado de intimidad imponderable, de inteligencia insoslayable, voluntad irreductible, libertad y capacidad de amar infinita. Por consiguiente, dignidad del individuo encuentra límite en la libertad del otro. Y, por otra parte, ese derecho de la persona no puede separarse del deber, de la responsabilidad adquirida. Ser digno prescribe ser en el planetario único después del Supremo y cuanto más encumbrado y lumbrera se siente el hombre, tanto más debe preconizar la 
humildad y sencillez por el compartir y el deber inolvidable de semejanza con Dios.

\section{Noción pedagógica respecto al alumno}

La percepción habitual o idea generalizada, que se tiene del hecho pedagógico en una institución educativa, es por lo general una imagen reduccionista de personas dentro de un salón, auditorio o aula, dispuestos a recibir clases, de determinada asignatura, impartidas por un profesor. Sin embargo, al proponerse un análisis de tal realidad, el asunto comienza a complicarse y van apareciendo diversos elementos constitutivos del fenómeno.

Al respecto, Frondizi (1972), recoge palabras del Obispo Butler: "cada cosa es lo que es y no otra cosa" (pág. 287); se intuye, que para inmiscuirse en la semántica y comprensión del contexto educativo, impera la necesidad de ser protagonista y acudir al ser de la realidad ontológica del mismo.

En sentido general, la concepción que tienen del alumno es la del respeto, lo que significa que se respeta el libre pensamiento, el derecho a intervenir y a ejercer los demás derechos que tiene por el hecho de ser un alumno. Así es, en la persona del docente recae el compromiso y la responsabilidad de mantener la armonía escolar. De tal manera que, el ideal de vida que se transmite en el proceso de enseñanza está encarnado en la persona del docente, la enseñanza escolar es un fenómeno continuo de transformación personal, en el que debe cuidarse el funcionamiento didácticopedagógico, de lo contrario, dejaría de ser proceso sistemático, que se realiza en compañía y cuidado del docente.

El amor propio en educación es un acto moral, se manifiesta por lo que cada docente experimenta y lo que los guía naturalmente en lo que hacen. De allí que Bauman (2005): sostiene, "Nadie debe hacerle daño a otro porque eso va en contra del interés propio. Ser despreciado por aquellos con quienes 
vivimos es una carga que nadie podría ni debería soportar" (pág. 35). Se evidencia entonces, que la responsabilidad moral en un docente, es la más personal e inalienable de las posesiones humanas, que le confiere la sociedad en el momento en que se compromete a educar a sus hijos.

El discurso a nivel mundial por el respeto a los derechos humanos, es hoy día un clamor insistente, son numerosas las instituciones y organismos internacionales que abogan por el cumplimiento de esta norma con naturaleza humana; asimismo, cada país en su Constitución parece incluir como principio humano fundamental, el derecho que tienen los ciudadanos por respeto a la vida, la participación, la educación y la expresión libre del pensamiento.

En sintonía con esta apreciación, la realidad del hombre muestra un crecimiento demográfico aproximado de siete mil millones, un logro de la especie humana que aunado a los avances tecnológicos en telecomunicaciones e informática, parece emerger la idea de apretujamiento poblacional y por ello ahora, se precisa de reclamar más derechos, a nombre de la educación, la creatividad, convivencia y libertad humana. No en vano es el exhorto de la comunidad internacional por replantear la visión de humanidad y mundo civilizado en medio de la incertidumbre que embarga problemas de discriminación racial, enfermedades endémicas, drogadicción, uso irracional de las formas naturales y contaminación.

\subsection{Aspectos legales afines al respeto de la dignidad humana}

Con la finalidad de suministrar disposiciones de organismos internacionales y la normativa legal venezolana asociados al proceso educativo y al respeto de la dignidad de la persona, a continuación, se muestra un cuadro comparativo de los aspectos relevantes considerados. Estos instrumentos legales concedidos a los actores en el proceso de formación, determinan la libertad para trascender en estudios de emprendimiento humano, en la medida en que sabe participar y cooperar en la construcción de 
una auténtica convivencia.

Cuadro nro. 1. Artículos correspondientes que afianzan los derechos del hombre.

\begin{tabular}{|c|c|}
\hline Naciones Unidas (1948a) & $\begin{array}{l}\text { Artículo 1: de la Declaración Universal de los } \\
\text { Derechos Humanos del año 1948: "los seres } \\
\text { humanos nacen libres e iguales en dignidad y } \\
\text { derechos y, dotados como están de razón y } \\
\text { conciencia, deben comportarse fraternalmente los } \\
\text { unos con los otros" (pág. 1). }\end{array}$ \\
\hline UNESCO (1996a) & $\begin{array}{l}\text { "Aprender a vivir juntos desarrollando la comprensión } \\
\text { del otro y la percepción de las formas de } \\
\text { interdependencia" (pág. 36). }\end{array}$ \\
\hline $\begin{array}{l}\text { Constitución de la República } \\
\text { Bolivariana de Venezuela } \\
\text { (1999b) }\end{array}$ & $\begin{array}{l}\text { Artículo 3: "El estado tiene como fines esenciales la } \\
\text { defensa y el desarrollo de la persona y el respeto a } \\
\text { su dignidad..." (pág. 3). }\end{array}$ \\
\hline $\begin{array}{l}\text { Ley Orgánica de Educación } \\
\text { (2009a) }\end{array}$ & $\begin{array}{l}\text { Artículo 15: "fomentar el respeto a la dignidad de la } \\
\text { persona" (pág. 8). } \\
\text { Artículo 50: "los miembros del personal docente } \\
\text { incurren en falta grave, en los casos de aplicación de } \\
\text { castigos corporales o afrentosos a los estudiantes, } \\
\text { por observar conducta contraria a la ética } \\
\text { profesional, a la moral, y las buenas costumbres" } \\
\text { (pág. 18). }\end{array}$ \\
\hline $\begin{array}{l}\text { Ley orgánica para la } \\
\text { protección del niño y del } \\
\text { adolescente }(1998 a)\end{array}$ & $\begin{array}{l}\text { Artículo 32: "derecho a la integridad psíquica y moral" } \\
\text { (pág. 7). } \\
\text { Artículo 80: "derecho a opinar y ser oído"; "derecho a } \\
\text { participar" (pág. 17). } \\
\text { Artículo 89: "Todos los niños y adolescentes... tienen } \\
\text { derecho a ser tratados con la humanidad y el respeto } \\
\text { que merece su dignidad como personas humanas" } \\
\text { (pág. 19). }\end{array}$ \\
\hline
\end{tabular}

Fuente: El Autor (2018).

Según el cuadro nro. 1, la Declaración Universal de los Derechos Humanos surge a partir del año 1948, cuando queda establecido dicho articulado y en el transcurso de los sesenta años siguientes, emergen nuevas disposiciones legales que sustentan aún más el respeto a esos derechos a la dignidad del ser humano. Según el Diccionario Enciclopédico Ilustrado (1991): 
"humano se aplica a la persona que se solidariza con las desgracias de sus semejantes" (pág. 89); es decir, una manifestación de la conducta humana constituye el querer hacer el bien y el ser benevolente o compasivo con el prójimo. Más aún, la normativa legal internacional, concede derechos a los individuos.

En esta perspectiva, la Declaración Universal de los Derechos Humanos, publicado por las Naciones Unidas (1948b), en los artículos 1 y 26 establece respectivamente lo siguiente: "todos los seres humanos nacen libres e iguales en dignidad y derechos y, dotados como están de razón y conciencia, deben comportarse fraternalmente los unos con los otros" (pág. 1). Tal contenido, se enfrenta hoy a la expectativa actual de las demandas humanas del presente siglo, signado por la problemática de la incomprensión y entendimiento que vive el género humano. La idea parece ser, reconstruir el significante de dignidad humana desde la conciencia moral, individual y colectiva, de deberes u obligaciones para lograr convivir como humanos en un planeta de humanos.

En esta tendencia discursiva, La ONU (1996), sostiene:

La educación en la esfera de los derechos humanos no debe circunscribirse al suministro de información, sino que debe constituir un proceso integral que se prolongue toda la vida mediante el cual las personas de todos los niveles de desarrollo y de todos los estratos de la sociedad aprendan a respetar la dignidad del prójimo y cuáles son los medios y mecanismos de velar por ese respeto en todas las sociedades (pág. 10).

En atención a estos aspectos legales afines al respeto por la dignidad humana, cabe resaltar que después de siete décadas de haberse promulgado, la percepción actual mundial, parece obviar que cada día hay menos personas favorecidas cada vez con más derechos y libertades, a cuesta de cada vez más desfavorecidos, cada vez, con menos derechos y libertades. Sin embargo, desde este panorama, Yepes (2018), admite: "que la preocupación 
por la dignidad de la persona humana es hoy universal: las declaraciones de los Derechos Humanos la reconocen, y tratan de protegerla e implantar el respeto que merece a lo largo y ancho del mundo" (pág. 1). Los educadores abnegados con vocación de servir, además de promocionar estos derechos, son los que: les orienta el interés pedagógico por exaltar el sentido de lo humano a los alumnos, la preeminencia del ser existencial, la búsqueda de sí mismos y la dignidad particular o colectiva.

Por su parte la UNESCO (1996b), plantea un cambio en la finalidad de la educación:

Desprenderse de una tendencia a la especialización y memorización de saberes para comenzar primero a desarrollar la dimensión aprender a convivir a vivir juntos en el contexto educativo como seres humanos, desarrollando la comprensión del alumno, la percepción de las formas de interdependencia, realizar proyectos comunes y prepararse para tratar los conflictos, respetando los valores de pluralismo y la comprensión mutua (pág. 36).

Es decir, este organismo propone el desarrollo de habilidades y estrategias para aprender a ser para que emerja la auténtica personalidad, en condiciones de mejor desempeño en la toma de decisiones y resolver problemas, aprender a conocer lo que supone además, aprender a aprender para poder aprovechar las posibilidades que ofrece la educación a lo largo de toda la vida, aprender a hacer a fin de proporcionar al alumno capacidades para afrontar las nuevas realidades del horizonte científico-técnico.

En otras palabras, lo que pretende innovar este organismo mundial con la propuesta de estos cuatro pilares en el sistema educativo, es el respeto a la condición de dignidad humana que tiene el alumnado en el proceso de conocer. En alusión a esto, Morín (1999), está convencido de la necesidad de replantear el pensamiento educativo y el proceso de enseñanza y aprendizaje:

No es suficiente el planteamiento teórico metodológico de la actualidad, para dar respuesta al proceso de enseñar- 
aprender. Por este motivo reflexiona sobre una enseñanza para educar. La misión de esta enseñanza será la de transmitir un saber diverso en lo cultural, que permita una manera de pensar abierta y libre, para comprender la condición humana y ayudar vivir (pág. 22).

De tal manera, que el pensar complejo en la investigación, busca primar la autonomía del pensamiento y superar las barreras de lo local y particular. Que pueda darle al discurso docente, sentido y significado cuando se trata de brindar respeto a la dignidad del estudiante. Esto implica obtener una visión integradora de las dimensiones que envuelven el comportamiento humano, evitando así, la reducción, disyunción y separación de la información.

A fin de ilustrar lo comentado, el texto de la Constitución de la República Bolivariana de Venezuela (1999c), expresa en el Artículo N. ${ }^{\circ}$ 3: "El estado tiene como fines esenciales la defensa y el desarrollo de la persona y el respeto a su dignidad..." (pág. 4). Como se puede entender en el artículo citado, la educación es concebida como un proceso de formación del sujeto, mediante el cual se le atribuye junto al trabajo, como el aspecto teleológico encargado al cumplimiento por parte del Estado, siendo entre otros el respeto a la dignidad de la persona, en este sentido, vislumbra una correspondencia teórica con el marco humanista que connota los fines de la educación señalados en este segmento del texto Constitucional, es decir, con la visión de una educación integral para lograr el desarrollo total de la persona.

De igual forma la Ley Orgánica de Educación (2009b), en el artículo 15, designa a la educación, conforme a los principios y valores de la Constitución de la República, y tiene como fines entre otros: "Fomentar el respeto a la dignidad de las personas y la formación transversalizada por valores éticos de tolerancia, justicia, solidaridad, respeto a los derechos humanos y la no discriminación" (pág. 21). Por ello que la visión de una educación integral en el marco del respeto a la dignidad de los estudiantes por parte de los 
profesores, está orientado a lograr con ello el desarrollo total de la persona, en el sentido de ser humano como tal.

Otro instrumento legal que defiende los derechos de la persona es la Ley orgánica para la protección del niño y del adolescente (1998b), en el artículo 32 refiere el "respeto a la integridad psíquica y moral" (pág. 7); y en el artículo 80 le confiere el "derecho a opinar" (pág. 17). En lo esencial, estos artículos llevan implícito una dignidad propia del ser humano como tal, por lo que debe ser tratado siempre como hombre igual a todos los de su especie; se precisa aquí, una relación entre la dignidad humana y los derechos del individuo. De ahí deriva, que en el campo educativo, si los alumnos merecen un trato especial, es debido a la humana relación dignidad-derecho.

Comprender el significado del respeto a la dignidad, desde los derechos humanos, supone en realidad mostrar a los alumnos el reto de saber vivir más humanamente, superar actitudes mezquinas por empeños de auténtica envergadura existencial: que desde el aula de clase se logre para todos más igualdad, tolerancia y solidaridad.

Se evidencia el implícito en los textos legales citados, un consenso general sobre los Derechos Humanos, que emanan de la dignidad inherente de la persona humana. Como valor central, la dignidad sirve de sustento axiológico a la justicia, la libertad, la igualdad, y la solidaridad entre otras dimensiones básicas de la persona, que en cuanto tales se convierten en rasgos para valorar y constituyen el ser de la legitimidad y dignidad reconocida.

Es decir, la dignidad humana aborda la naturaleza que envuelve la vida, no es un derecho del hombre, es fundamento ético de los derechos que se conceden al hombre. Asimismo, Arrieche (2017), afirma: "el maestro es ético cuando actúa con responsabilidad en un contexto institucional, teniendo en cuenta que comparte con sus estudiantes tanto su ser como su hacer y el conocimiento que posee" (pág. 370). Un educador por naturaleza aceptada para ocupar espacios en el escenario institucional de la enseñanza, es 
auténtico mientras desempaña la dignidad del otro a favor de ese otro y de sí mismo; la inmanencia del ser pedagogo dentro del ser que humaniza, es posible en este particular, gracias a la virtud teologal de caridad, convertida en amor por el prójimo.

\section{Comprensión final}

La educación es una de las áreas que se ve influida por diversas posiciones personales y profesionales entre otras, que buscan orientar sus principios o su razón de ser. Asimismo, los nuevos retos demandan de los investigadores educativos, ser personas verdaderamente creativas, con capacidad para introducir mejoras en la problemática del contexto educativo.

El hecho educativo tiene planteado un reto, ante los avances científicotécnicos, de la Física, Biología, Neurociencia, Comunicación e Información; necesita repensarse y abordar las nuevas concepciones humanas $y$ tendencias epistemológicas que señalan cambios en la manera de producir conocimiento.

El docente debe estar consciente del momento histórico y vital que le ha correspondido vivir y compartir con los alumnos, la heterogeneidad, la diversidad de intereses y actitudes es el reto al que se enfrenta el profesorado, ni un solo apartado de la personalidad y de la vida queda al margen o se omite cuando entra en el aula y convive en profundidad con el pensamiento y sentimientos de sus alumnos. Nada es ajeno a la personalidad del alumno en el encuentro nivelado y cara a cara con el maestro. Todos los rasgos y atributos de ambos eslabones, educador y educando se fusionan para hacer emerger la diáspora del bienestar general compartido.

Las nuevas tendencias del conocimiento señalan en las últimas décadas la posibilidad de la visión interdisciplinaria en los estudios científicos, para comprender la interacción socioeducativa y humana. La teoría social reclama la solidaridad social y la integración del conocimiento como vías para 
mejorar el complejo espectáculo de los valores de la actualidad educativa. El mejor aval que garantiza una axiología de los valores, es la vivencia misma, en el momento y espacio compartido. De ahí que las estrategias metodológicas destinadas a orientar para la paz y convivencia humana, deben ser ipso facto, en caliente para mejor provecho, comprensión y entendimiento.

Para el investigador, la intención innovadora en la educación, debe ir cargada de toda una acción creativa, procurando no repetir en la producción teórica lo de otras investigaciones; siendo así, los aportes al conocimiento serían pertinentes y útiles por más tiempo. Los conceptos y proposiciones planteados, permite abordar y clarificar relevantes aspectos familiares, educativos y culturales inherentes al docente y relacionados en el cómo ve éste, el trato que le da al alumno en cuanto al respeto a su dignidad.

Las inquietudes surgidas van desde la escuela para fortalecer la nueva visión filosófica de la vida más humanizada, que enfatice el valor de la dignidad de los estudiantes, la amistad y la vida del individuo en armonía con sus propias potencialidades y en colectivo, y rescatar la visión humana no antropocéntrica del proceso de formación escolar, como vía expedita para el desarrollo ético moral y del potencial humano, para trascender en el milenio que recién comienza.

\section{Referencias}

Arrieche, M. (2017). Gestión Docente en el Contexto de la Educación Primaria Venezolana. Revista Scientific, 3(7), 354-373. Recuperado de: https://doi.org/10.29394/Scientific.issn.2542-2987.2018.3.7.18.354$\underline{373}$

Bauman, Z. (2005). Ética postmoderna. Primera edición. Argentina: Siglo XXI Editores.

Constitución de la República Bolivariana de Venezuela (1999a,b,c). Gaceta

Oficial Extraordinaria $\mathbf{N}^{\circ} \mathbf{3 6 . 8 6 0}$ de fecha 30 de diciembre. Caracas, 
Venezuela: Asamblea Nacional Constituyente.

Diccionario Enciclopédico Ilustrado (1991). Humano. Colombia: Editorial Océano Uno.

Diccionario de la real academia española (2001a). Dignidad. Madrid, España: Real Academia Española.

Diccionario de la real academia española (2001b). Respeto. Madrid, España: Real Academia Española.

Diccionario de la real academia española (2001c). Condición. Madrid, España: Real Academia Española.

Frondizi, R. (1972). Valor, estructura y situación. Dianoia, (18), 284-292.

Recuperado de: http://biblio3.url.edu.gt/Libros/2012/Hombre/04/11.pdf

Ley orgánica para la protección del niño y del adolescente (1998a,b). Gaceta

Oficial $\mathrm{N}^{\circ}$ 5266. Extraordinario del 02 de octubre. Caracas, Venezuela: El Congreso de la República de Venezuela.

Ley Orgánica de Educación (2009a,b). Gaceta Oficial № 5.929 Extraordinario del 15 de agosto. República Bolivariana de Venezuela:

La Asamblea Nacional.

Ministerio del Poder Popular para la Educación (2007a,b). Currículo Básico Nacional Bolivariano. ISBN: 978-980-218-281-7. Caracas, Venezuela: Fundación Centro Nacional para el Mejoramiento de la Enseñanza de Ciencia - CENAMEC. Recuperado:

http://www.oei.es/quipu/venezuela/dl 908 69.pdf

Morín, E. (1999). Los siete saberes necesarios para la educación del futuro. Barcelona, España: Paidós.

Naciones Unidas (1948a,b). Declaración universal de los derechos

humanos. París: Asamblea General de las Naciones Unidas.

Recuperado de:

http://www.un.org/es/universal-declaration-human-rights/

ONU (1996). Informe del Alto Comisionado de las Naciones Unidas para 
los Derechos Humanos sobre la aplicación del Plan de Acción para el Decenio de las Naciones Unidas para la educación en la esfera de los derechos humanos. Ginebra: Proyecto conjunto del Departamento de Información Pública y el Centro de Derechos Humanos - Naciones Unidas. Recuperado de:

https://digitallibrary.un.org/record/223443/files/A 51 506-ES.pdf

Penalva, J. (2006). La identidad del profesor. Referentes de identidad constitutivos de la profesión educativa. Tesis doctoral. ISBN: 84689-9236-4. España: Universidad de Murcia. Recuperado de:

http://dialnet.unirioja.es/servlet/tesis?codigo $=6028$

Santa Biblia (1985). Versión Ilustrada. España: Líder editores, S.A.

UNESCO. (1996a,b). La educación encierra un tesoro: Educación para el siglo XXI. Francia: CRESALC.

Villegas, B. (s.f.). La dignidad humana según la Biblia. Chile: Centro de Estudios Públicos. Recuperado de:

https://www.cepchile.cl/una-dignidad-vulnerable-la-dignidad-humanasegun-la-biblia/cep/2016-03-03/183159.html

Yepes, R. (2018). La dignidad de la persona. MuerteDigna.org [Documento en línea]. Recuperado de:

http://www.muertedigna.org/textos/euta51.html 


\section{Ciro Hernández Valderrama}

e-mail: cirohv@hotmail.com

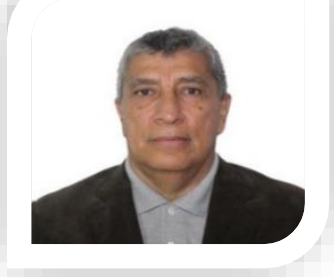

Nacido en el Estado Trujillo, Venezuela. Licenciado en educación, mención: Orientación egresado de Universidad de Carabobo; Maestría en Educación Básica (Universidad Nacional Experimental Rómulo Gallegos); Doctor en Ciencias de la Educación (Universidad Fermín Toro); Postdoctorado en

Estudios Libres (UFT). Cuya agenda constituye un proceso sistematizado de investigación, producción, análisis y comunicación de conocimientos. Así mismo, la epistemología como una reflexión filosófica en torno al estado del arte científico, que pretende dar cuenta de los modos de pensar y conocer los estilos de pensamiento, teorías y prácticas en campos disciplinares específicos. Profesor Asociado, coordinador del área Formación Humanística, adscrito a Departamentos de Mecánica Térmica y Automotriz en la Universidad Politécnica de Puerto Cabello, Venezuela. Diseñador y motivador en proyectos de orientación con valores de convivencia institucional, docente-alumno y socio-comunitaria. Ponente en congresos académicos. Participante con artículos en revistas científicas. Dictaminador en revistas científicas: ARJE, Ciencias de la Educación, EDUCARE UPEL IPB, Investigaciones Interactivas COBAIND, SCIENTIARUM, EDUCARE UNA. Jurado en trabajos de ascenso: UNIPAP, IUTPC. Tutor de tesis UC. Investigador socioeducativo, en la dimensión ético-moral del hombre. Certificado en el Programa de Estímulo a la Innovación e Investigación. PEll convocatoria 2015-2016, Investigador A-1, adscrito al Observatorio Nacional de Ciencia Tecnología e Innovación (ONCTI). 